\title{
EVALUASI KINERJA ASET INSTALASI PENGOLAHAN LUMPUR TINJA (IPLT) CIBEET DI KABUPATEN BANDUNG
}

\author{
Rizkia Noviana \\ Program Studi Manajemen Aset, Politeknik Negeri Bandung \\ Penulis Korespondensi e-mail: rizkianoviana9@gmail.com
}

\begin{abstract}
Cibeet Faecal Sludge Treatment Plant (FSTP) Bandung Regency is one of the wastewater treatment infrastructures in Bandung Regency. The purpose of this research is to see the performance of Cibee FSTP assets based on three measurement dimensions which include: technical, economic, and environmental dimensions. This type of research method is a descriptive method. Qualitative approach analysis techniques and quantitative approaches. The results of the performance evaluation from the technical dimension explain that the technical performance is poor. The evaluation results from the economic dimension show that economic performance is poor. Meanwhile, the evaluation results from the environmental dimension are poor.
\end{abstract}

Keywords: Performance Evaluation, Supporting Facilities, FSTP, and Installation Unit.

\begin{abstract}
Abstrak
Instalasi Pengolahan Lumpur Tinja (IPLT) Cibeet Kabupaten Bandung merupakan salah satu infrastruktur pengolahan air limbah di Kabupaten Bandung. Tujuan dari penelitian ini untuk mengetahui kinerja aset IPLT Cibeet berdasarkan tiga dimensi pengukuran yang meliputi: dimensi teknis, ekonomi, dan lingkungan. Jenis metode penelitian adalah metode deskriptif. Teknik analisis berdasarkan pendekatan kualitatif dan pendekatan kuantitatif. Hasil evaluasi kinerja dari dimensi teknis menjelaskan bahwa kinerja teknis buruk. Hasil evaluasi dari dimensi ekonomi bahwa kinerja ekonomi buruk. Sedangkan hasil evaluasi dari dimensi lingkungan buruk.

Kata Kunci: Evaluasi Kinerja, Fasilitas Pendukung, IPLT, dan Unit Instalasi
\end{abstract}




\section{PENDAHULUAN}

Pemerintah Kabupaten Bandung memiliki visi "Meningkatkan Kualitas Lingkungan Hidup" yang berarti meningkatkan kualitas lingkungan hidup di Kabupaten Bandung salah satunya dengan cara mengurangi pencemaran lingkungan. Di dalam pengelolaan lingkungan hidup, pengolahan limbah domestik merupakan sebagian dari upaya untuk memelihara lingkungan hidup. Limbah domestik termasuk penyumbang utama pencemaran karena dibuang ke sungai atau selokan. Pada saat ini Pemerintah Kabupaten Bandung memiliki aset infrastruktur penunjang pengolahan air limbah domestik yaitu Instalasi Pengolahan Lumpur Tinja (IPLT) Cibeet. IPLT adalah instalasi pengolahan air limbah yang dirancang hanya menerima dan mengolah lumpur tinja yang berasal dari Sub-sistem Pengolahan Setempat (Direktorat Jenderal Cipta Karya, 2016).

Terdapat fenomena yang telah teridentifikasi pada IPLT Cibeet. Berdasarkan hasil observasi dan wawancara dengan kepala UPTD IPAL Domestik (Disperkimtan) dan pegawai IPLT Cibeet, dari dimensi teknis pada IPLT Cibeet tidak terdapat kegiatan operasional di IPLT Cibeet ditandai dengan tidak adanya orang yang bekerja; kondisi kolam fakultatif yang sudah mengering dan konstruksi yang retak, kondisi bak pengering yang sudah mengering tertimbun tanah dan alat pintu air yang berkarat; dan kondisi kolam maturasi sebagian tertimbun tanah dan tanaman liar, terdapat sampah, dan dinding bangunan yang retak. Dari dimensi ekonomi,pendapatan yang diterima lebih kecil dari biaya yang dikeluarkan setiap bulannya. Dari dimensi lingkungan, adanya IPLT Cibeet menimbulkan bau tidak sedap ketika terjadi kebocoran pada unit instalasi. Berdasarkan pada fenomena aset IPLT Cibeet yang telah dijelaskan. Maka dibutuhkan penelitian studi kasus IPLT Cibeet agar mengetahui kinerja IPLT Cibeet. Peneliti bermaksud mengajukan penelitian Studi Kasus dengan judul "Evaluasi Kinerja Aset Instalasi Pengolahan

\section{Lumpur Tinja (IPLT) Cibeet di Kabupaten Bandung”.}

Menurut Australian Asset Management Collaborative Group (2012), pada intinya berpendapat bahwa evaluasi adalah suatu proses yang meliputi pengukuran, pelaporan, dan peninjauan kembali kinerja aset yang dibandingkan dengan pengelolaan aset, tujuan organisasi dan pemerintah. Kinerja atau performance adalah hasil yang dicapai dari sebuah atau serangkaian aktivitas maupun pekerjaan pada sebuah organisasi atau sebuah investasi selama jangka waktu tertentu (Sugiama, 2013). Menurut Uddin et al. (2013), berpendapat pada umumnya definisi kinerja yang terkait dengan fasilitas infrastruktur adalah sejauh mana suatu fasilitas melayani penggunanya dan memenuhi tujuan pembangunan atau 
perolehannya, yang diukur dengan akumulasi kualitas dan lama layanan yang diberikan kepada penggunanya. Evaluasi kinerja adalah alat untuk menilai kinerja organisasi terhadap pelayanan yang dihasilkan dan membantu sistem akuntabilitaas untuk perbaikan yang berkelanjutan (Australian Asset Management Collaborative Group, 2008). Evaluasi kinerja IPLT Cibeet diukur berdasarkan dimensi teknis, ekonomi, dan lingkungan menurut Shi Kun et al. (2017). Pada dimensi teknis mengkaji kembali kemampuan kondisi eksisting dalam pengolohan lumpur tinja yang masuk terhadap kapasitas desain. Dimensi teknis diukur berdasarkan indikator kesesuaian Kondisi Fisik IPLT dengan Kriteria Eksisting Fisik IPLT dan fungsi atau status beroperasinya IPLT. Dalam menentukan kinerja pada dimensi ekonomi maka diperlukan analisis rasio keuangan terhadap anggaran atau biaya yang telah ditetapkan dan dilaksanakan. Dimensi lingkungan merupakan alat untuk mengantisipasi dampak lingkungan dari perubahan kebijakan dan perkembangan baru, lingkungan berkaitan dengan peran operasional aset. Adapun tujuan penelitian ini adalah untuk mengetahui kinerja IPLT Cibeet yang mencakup dimensi teknis, ekonomi, dan lingkungan.

\section{METODOLOGI}

Jenis metode penelitian yang digunakan adalah metode penelitian deskriptif dengan pendekatan kualitatif dan kuantitatif. Metode deskriptif kualitatif digunakan untuk menganalisa kondisi eksisting, stakeholder dari IPLT, fungsi dari IPLT, dan dampak adanya IPLT terhadap lingkungan. Sedangkan metode deskriptif kualitatif digunakan untuk menganalisa ukuran dari IPLT yang harus sesuai dengan dengan standar/kriteria desain yang berlaku, biaya operasional, biaya pemeliharaan, dan pendapatan di IPLT Cibeet. Terdapat dua jenis data yang dibutuhkan pada penelitian ini yaitu data primer dan data sekunder. Data primer diperoleh dari hasil wawancara dan observasi. Data primer digunakan untuk mengetahui standar yang digunakan dalam proses pengoperasian, Tupoksi dari IPLT, aset yang ada di IPLT, biaya pemeliharaan, biaya operasional, pendapatan,dan informasinya lainnya terkait IPLT Cibeet. Data sekunder diperoleh dari sumber lainnya seperti buku, unduhan publikasi atau file digital. Teknik pengumpulan data yang digunakan adalah trianggulasi yaitu observasi, wawancara, dan studi dokumentasi. 


\section{HASIL DAN PEMBAHASAN}

\subsection{Evaluasi Kinerja Aset Instalasi Pengolahan Lumpur Tinja (IPLT) Cibeet}

Hasil dan bahasan menjelaskan mengenai evaluasi kinerja aset Instalasi Pengolahan Lumpur Tinja (IPLT) Cibeet ditinjau dari 3 (Tiga) dimensi menurut Shi Kun et al. (2017) yakni teknis, ekonomi, dan lingkungan.

\subsubsection{Dimensi Teknis}

Kinerja teknis menggambarkan karakteristik-karakteristik struktural, fisik dan teknis lainnya. Dalam dimensi teknis mengkaji kembali kemampuan kondisi eksisting dalam pengolohan lumpur tinja yang masuk terhadap kapasitas desain. Dimensi teknis diukur dengan menggunakan 2 (dua) indikator sebagai berikut.

\section{Indikator Kesesuaian Eksisting Fisik IPLT dengan Kriteria Fisik IPLT}

Evaluasi dari indikator kesesuaian eksisting fisik IPLT dengan kriteria fisik IPLT terdiri dari evaluasi ketersediaan unit instalasi serta fasilitas pendukung dan evaluasi kondisi fisik unit instalasi serta fasilitas pendukung.

a. Ketersediaan unit instalasi dan fasilitas pendukung

Evaluasi ketersediaan dilakukan dengan cara membandingkan ketersediaan unit instalasi pengolahan lumpur tinja di IPLT Cibeet dengan standar sistem kolam. Berdasarkan wawancara dengan karyawan IPLT Cibeet,pada awal perencanaannya IPLT Cibeet memiliki kapasitas sebesar 25 m3/hari. Maka standar sistem kolam yang digunakan untuk mengevaluasi ketersediaan unit instalasi dan fasilitas pendukung yakni mengacu pada Panduan Perencanaan Teknik Terinci Bangunan IPLT dan Panduan Sistem Pengelolaan Air Limbah Domestik Terpusat (Direktorat Jenderal Cipta Karya,Kementerian Pekerjaan Umum,2016). Perbandingan yakni dengan kapasitas yang sama 25 m3/hari. Tujuan perbandingan tersebut untuk mengetahui IPLT Cibeet sudah memenuhi atau belum memenuhi standar/kriteria desain yang telah ditetapkan. Perbandingan ketersediaan unit instalasi pengolahan lumpur tinja di IPLT Cibeet dengan standar sistem kolam ditunjukkan pada Tabel 1. 
Tabel 1 Perbandingan Ketersediaan Unit Instalasi Eksisting dengan Standar Sistem Kolam

\begin{tabular}{|l|l|l|l|}
\hline \multirow{2}{*}{ No } & \multicolumn{1}{|c|}{ Jenis } & \multicolumn{1}{|c|}{ Standar Sistem Kolam } & \multicolumn{1}{c|}{ Kondisi Eksisting } \\
\cline { 3 - 4 } & & \multicolumn{1}{|c|}{ Ukuran } & \multicolumn{1}{c|}{ Ukuran } \\
\hline 1 & \multirow{2}{*}{ Bak Penampung } & $150 \mathrm{~m}^{2}$ & \\
\hline 2 & Kolam Anaerob & $60 \mathrm{~m}^{2}$ & $21 \mathrm{~m}^{2}$ \\
\hline 3 & Kolam Fakultatif & $300 \mathrm{~m}^{2}$ & $500 \mathrm{~m}^{2}$ \\
\hline 4 & Kolam Maturasi & $150 \mathrm{~m}^{2}$ & $200 \mathrm{~m}^{2}$ \\
\hline 5 & Bak Pengering & $150 \mathrm{~m}^{2}$ & $70 \mathrm{~m}^{2}$ \\
\hline
\end{tabular}

Sumber: Analisis Penyusun, 2020

Berdasarkan Tabel 1 hasil perbandingan menyatakan bahwa bak penampung/ pengumpul tidak tersedia di IPLT Cibeet. Selain itu, ukuran dari unit instalasi, beberapa ada yang tidak memenuhi standar yaitu kolam anaerob dan bak pengering. Perbandingan ketersediaan fasilitas pendukung di IPLT Cibeet sesuai standar sistem kolam dapat dilihat pada Tabel 2.

Tabel 2 Perbandingan Ketersediaan Fasilitas Pendukung dengan Standar Sistem Kolam

\begin{tabular}{|l|l|l|l|}
\hline \multirow{2}{*}{ No } & \multirow{2}{*}{ Jenis } & \multicolumn{1}{|c|}{ Standar Sistem Kolam } & \multicolumn{1}{c|}{ Kondisi Eksisting } \\
\cline { 3 - 4 } & & \multicolumn{1}{|c|}{ Ukuran } & \multicolumn{1}{c|}{ Ukuran } \\
\hline 1 & Gudang & $36 \mathrm{~m}^{2}$ & $12 \mathrm{~m}^{2}$ \\
\hline 2 & Jalan & $6 \mathrm{~m}$ (lebar) & $7 \mathrm{~m}$ \\
\hline 3 & Pagar Pembatas & $5 \mathrm{~m}$ (tinggi) & $1,2 \mathrm{~m}$ \\
\hline 4 & Gerbang & $5 \mathrm{~m}$ (tinggi) & $1,5 \mathrm{~m}$ \\
\hline 5 & Drainase & $5 \mathrm{~cm}\left(\right.$ lebar) $^{2}$ & $50 \mathrm{~cm}^{2}$ \\
\hline 6 & Pos Jaga & $12 \mathrm{~m}^{2}$ & $12 \mathrm{~m}^{2}$ \\
\hline 7 & Kantor & $48 \mathrm{~m}^{2}$ & $48 \mathrm{~m}^{2}$ \\
\hline 8 & Laboratorium & $24 \mathrm{~m}^{2}$ & \\
\hline 9 & Tempat Parkir & $10 \mathrm{~m}^{2}$ & $10 \mathrm{~m}^{2}$ \\
\hline
\end{tabular}

Sumber: Analisis Penyusun, 2020

Berdasarkan Tabel 2 dapat dilihat bahwa terdapat satu fasilitas pendukung yang tidak tersedia dengan standar sistem kolam di IPLT Cibeet yakni laboratorium. Terdapat ukuran fasilitas pendukung yang tidak sesuai dengan standar sistem kolam yaitu luas gudang, tinggi pagar pembatas, dan tinggi gerbang tidak memenuhi standar.

b. Kondisi Fisik Unit Instalasi dan Fasilitas Pendukung

Kondisi fisik unit instalasi dan fasilitas pendukung dengan standar visual sistem kolam menurut Direktorat Jenderal Cipta Karya (2015) dapat dilihat pada Gambar 1 dan Gambar 2. 


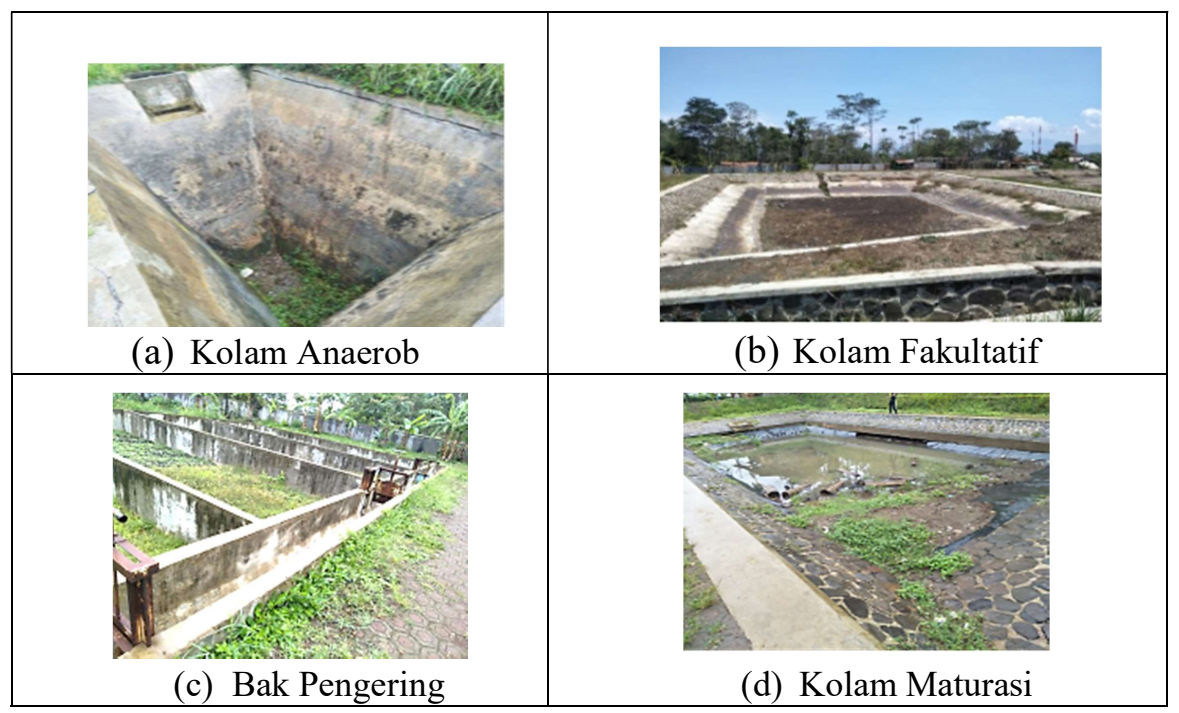

Gambar 1 Kondisi Eksisting Unit Instalasi

Berdasarkan Gambar 1 dapat diketahui kondisi unit instalasi pada IPLT Cibeet. uraian perbandingan kondisi fisik unit instalasi dengan standar visual sebagai berikut.

1) Kondisi eksisting pada kolam anaerob yakni bahan bangunan terbuat dari beton dan posisi kolam anaerob berada di atas kolam fakultatif agar mempermudah proses pengaliran lumpur tinja. Namun, pada kolam anaerob terdapat keretakan pada sebagian dinding bangunan. Terdapat salahsatu komponen yang tidak berfungsi yakni pompa gatevalve. Mengacu standar visual yang telah ditetapkan, kolam Anaerob dikategorikan dalam kondisi rusak ringan karena bangunan dikategorikan rusak ringan, jika terdapat keretakan pada sebagian dinding bangunan dan terdapat beberapa komponen yang tidak berfungsi.

2) Kondisi eksisting pada kolam fakultatif yakni bahan bangunan terbuat dari beton dan posisi kolam fakultatif berada di atas kolam maturasi. Namun pada kolam fakultatif terdapat kerusakan pada sebagian bangunan dan terdapat kebocoran. Mengacu standar visual yang telah ditetapkan, kolam Fakultatif dikategorikan dalam kondisi rusak berat karena kondisi bangunan dapat dikategorikan rusak berat, jika terdapat kerusakan pada sebagian atau seluruh struktur bangunan dan terdapat kebocoran yang ditandai adanya bau tidak sedap.

3) Kondisi eksisting pada kolam maturasi yakni bahan bangunan terbuat dari beton dan posisi kolam maturasi berada dibawah kolam fakultatif. Mengacu standar visual yang telah ditetapkan, kolam Maturasi dikategorikan dalam kondisi rusak ringan karena kondisi bangunan dikategorikan dalam kondisi rusak ringan jika terdapat keretakan 
dan kerusakan pada sebagian bangunan. Terdapat kerusakan pada geomembran yang menimbulkan kebocoran. Pemasangan geomembran secara standar visual sangat dihindari karena pemasangan geomembran pada unit pengolahan memiliki potensi rusak pada saat dilakukan kegiatan operasi dan pemeliharaan.

4) Kondisi eksisting bak pengering tidak terdapat kerusakan pada struktur bangunan , bak bangunan terbuat dari beton. Namun, terdapat komponen yang rusak yakni pintu air yang berkarat dan tidak berfungsi. Selain itu, bak bangunan tidak dilengkapi dengan penutup atap untuk mengatasi permasalahan jika terjadi hujan. Berdasarkan perbandingan antara kondisi eksisting bak pengering dengan standar visual bak pengering, bak pengering pada IPLT Cibeet dikategorikan dalam keadaan rusak ringan. Bangunan dikategorikan rusak ringan, jika jika terdapat keretakan pada dinding bangunan dan terdapat beberapa komponen yang tidak berfungsi.

Selain terdapat unit instalasi proses pengolahan, pada IPLT juga terdapat proses pengeringan hasil lumpur tinja menjadi pupuk yang dilakukan di bak pengering. Pupuk tersebut nantinya dimanfaatkan oleh petani sekitar atau yang membeli pupuk untuk penanaman pada perkebunannya. Kondisi dari fasilitas pendukung dapat dilihat pada Gambar 2. 


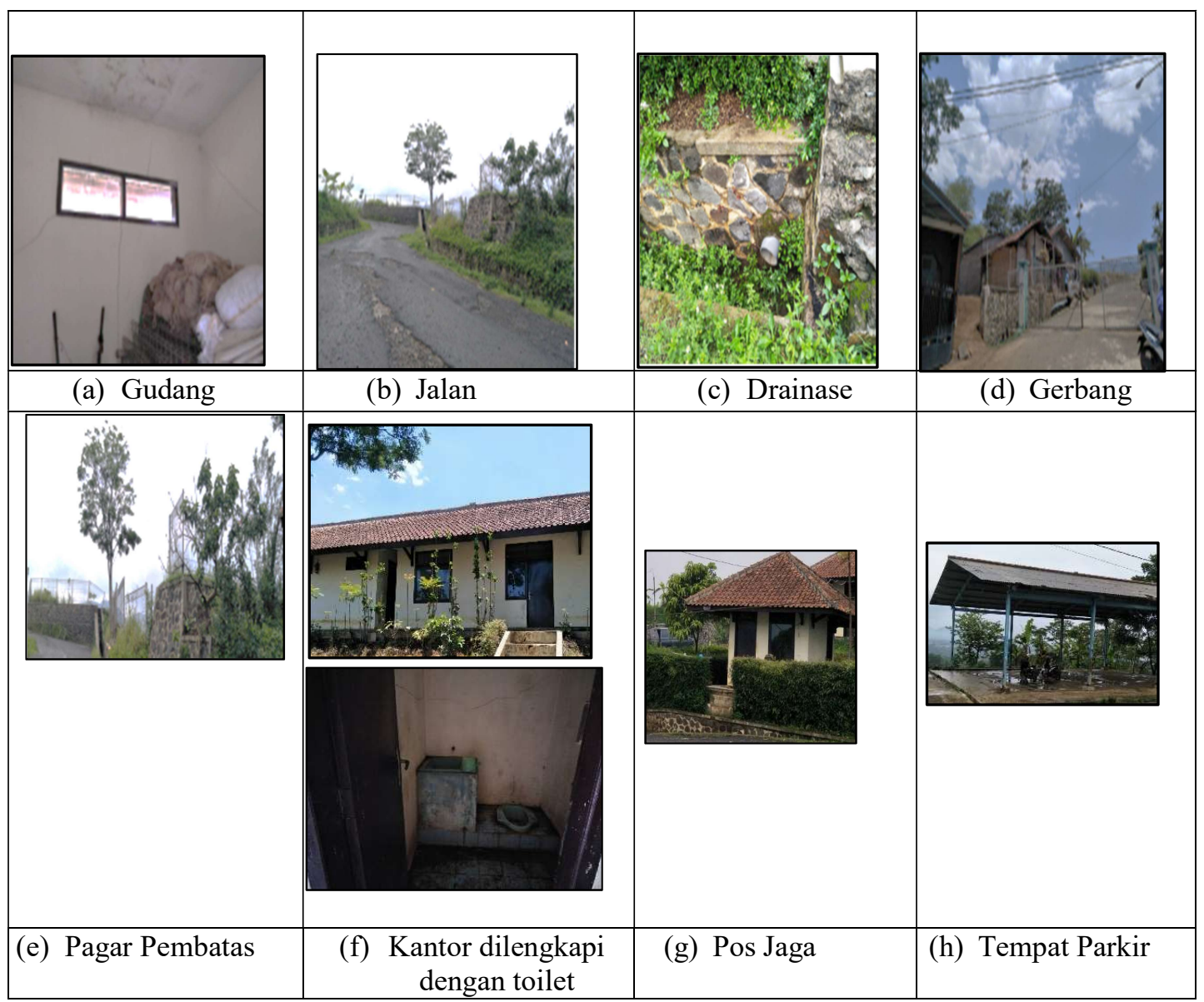

Gambar 2 Kondisi Eksisting Fasilitas Pendukung

Berdasarkan gambar 2 maka dapat diketahui kondisi ekstisting dari fasilitas pendukung. Uraian perbandingan antara fasilitas pendukung dengan standar visual sebagai berikut.

1) Kondisi dalam ruangan gudang terdapat keretakan pada dinding bangunan, kondisi ruang tidak steril dan lantai gedung tidak bersih karena terdapat debu. Kondisi di luar gudang terdapat ventilasi udara dan struktur bangunan masih kokoh. Kondisi bangunan gudang dikategorikan rusak ringan karena kondisi bangunan dikategorikan rusak ringan jika terdapat keretakan pada sebagian dinding bangunan dan atap bangunan. Selain itu, kondisi dalam ruangan gudang harus steril.

2) Kondisi jalan di IPLT Cibeet terdapat sedikit kerusakan pada sebagian jalan seperti jalan yang retak dan berlubang. Jalan dapat dilalui oleh kendaraan roda empat. Kondisi jalan pada IPLT Cibeet dapat dikategorikan dalam keadaan rusak ringan karena kondisi jalan dikategorikan dalam keadaan rusak ringan jika terdapat kerusakan pada sebagian badan jalan. 
3) Kondisi eksisting pintu gerbang dalam keadaan baik, tidak terdapat kerusakan dan bahan pintu gerbang terbuat dari besi yang sesuai dengan standar visual. Namun ukuran tinggi dari pintu gerbang tidak sesuai karena ukuran tinggi pintu gerbang pada IPLT Cibeet 1,5 m sedangkan standar yang telah ditetapkan tinggi gerbang yakni $5 \mathrm{~m}$. Kondisi pintu gerbang dikategorikan dalam keadaan baik karena tidak terdapat kerusakan pada pintu gerbang.

4) Kondisi eksisting pagar pembatas dalam keadaan baik, tidak terdapat kerusakan dan bahan pagar pembatas terbuat dari besi yang sesuai dengan standar visual. Namun ukuran tinggi dari pagar pembatas tidak sesuai karena ukuran tinggi pagar pembatas pada IPLT Cibeet 1,2 $\mathrm{m}$ sedangkan standar yang telah ditetapkan tinggi pagar pembatas yakni $5 \mathrm{~m}$. Kondisi pagar pembatas dikategorikan dalam keadaan baik karena tidak terdapat kerusakan pada pagar pembatas.

5) Kondisi eksisisting drainase dalam keadaan baik dan tidak terdapat penyumbatan. Namun, terdapat rumput liar tumbuh disekitar drainase yang akan menimbulkan resiko penyumbatan jika rumput liar tersebut dibiarkan.

6) Kondisi eksisting pos jaga dalam keadaan baik dan sesuai dengan standar sistem kolam.

7) Kondisi eksisting kantor dalam keadaan rusak ringan karena terdapat kerusakan pada komponen non struktural seperti pintu yang rusak dan mengelupas, terdapat keretakan halus pada sebagian dinding bangunan. Kantor telah dilengkapi dengan toilet.

8) Tempat parkir dalam kondisi baik dan sudah sesuai dengan standar sistem kolam.

\section{Fungsi atau Status Beroperasinya IPLT}

Pengukuran indikator fungsi atau status beroperasinya IPLT ditinjau dari terpenuhinya tugas pokok dan fungsi IPLT Cibeet, intensitas penggunaan IPLT Cibeet dan status beroperasinya tiap unit instalasi. Tugas pokok dan fungsi IPLT Cibeet sebagai bangunan sistem pengolahan yang menampung hasil sedotan lumpur tinja dari rumah tinggal maupun septiktank komunal sebelum lumpur tersebut aman untuk dibuang/dimanfaatkan sebagai produk akhir. Penggunaan IPLT Cibeet saat ini hanya sebagai tempat pembuangan air limbah domestik (lumpur tinja). Persentase penggunaan aset IPLT Cibeet sebesar $0 \%$ dari keseluruhan tugas pokok dan fungsinya. Penyebab utama penggunaan aset IPLT tidak dilakukan sesuai dengan tugas pokok dan fungsinya secara keseluruhan karena kondisi fisik aset IPLT Cibeet yang sebagian besar mengalami kerusakan. 
Sedangkan, untuk mengevaluasi intensitas penggunaan aset IPLT Cibeet ditinjau dari pembuangan lumpur tinja yang dibuang ke IPLT Cibeet berdasarkan jam kerja di IPLT Cibeet. Jam kerja IPLT Cibeet selama 8 jam. Pada tahun 2019, pembuangan lumpur tinja dilakukan sebanyak 3 (tiga) kali pada bulan januari, maret, dan april dalam satu tahun terakhir. Sedangkan dari tahun 2017 dan tahun 2018 tidak adanya pembuangan. 1 kali penggunaan pada IPLT Cibeet membutuhkan waktu 40 jam kerja. Perhitungan intensitas penggunaan IPLT Cibeet pada tahun 2019 sebagai berikut:

\section{Target jam kerja dalam 1 (satu) tahun :}

1 hari : 8 jam kerja

1 minggu: 8 jam $x 5$ hari kerja $=40$ jam

1 bulan: 40 jam $\times 4=160$

1 tahun: $160 \times 12=1.920$ jam kerja

\section{Jam kerja eksisiting pada tahun 2019:}

Pada tahun 2019, pembuangan dilakukan 3 kali. Jam kerja 1 kali penggunaan adalah 40 jam.

Jam kerja penggunaan pada tahun $2019=40$ jam $\times 3=120$ jam kerja/ tahun

\section{Perhitungan intensitas penggunaan:}

Intensitas pengunaan $=120 / 1.920 \times 100 \%=6,25 \%$

\section{Jam kerja menganggur $/$ idle $=1.920 \mathrm{jam}-120 \mathrm{jam}=1800 \mathrm{jam} /$ tahun}

Berdasarkan hasil perhitungan diatas, persentase intensitas penggunaan dari IPLT Cibeet dalam satu tahun sebesar 6,25\% jauh dari target jam kerja yakni $100 \%$. Sedangkan jam kerja yang menganggur/idle sebesar 1800 jam / tahun lebih besar dari jam kerja penggunaan IPLT Cibeet.

Selanjutnya untuk mengetahui status beroperasinya setiap unit instalasi pada IPLT Cibeet perlu dilakukannya perbandingan adanya eksisting dengan fungsi dari tiap instalasi. Namun kondisi unit instalasi dalam keadaan rusak ringan dan rusak berat maka tiap unit instalasi tidak berfungsi.

\subsubsection{Dimensi Ekonomi}

Dalam mengevaluasi kinerja ekonomi maka diperlukan analisis rasio keuangan terhadap anggaran atau biaya yang telah ditetapkan dan dilaksanakan. Dimensi ekonomi diukur berdasarkan rasio efektivitas keuangan dan efisiensi keuangan yang diadaptasi dari Nurhayati (2015). Data yang diperlukan untuk mengukur kinerja ekonomi pada IPLT 
Cibeet yaitu berdasarkan hasil wawancara dengan kepala UPTD IPAL Domestik, biaya operasional pada IPLT Cibeet tiap tahunnya sebesar Rp 40.800.000. biaya pemeliharaan sebesar Rp 1.200.000 tiap tahun. Pendapatan yang diterima Rp 450.000. Sedangkan untuk target penerimaan PAD ditetapkan sebesar Rp 27.500.000 setiap tahunnya. Menurut (Alhusain et al., 2017), berpendapat bahwa strategi dan kebijakan peningkatan PAD merupakan salah satu modal keberhasilan dalam mencapai tujuan pembangunan daerah.

\section{Rasio Efektivitas}

Rasio efektivitas dihitung dengan cara membandingkan realisasi penerimaan pendapatan (retribusi) dengan target penerimaan pendapatan (Nurhayati, 2015). Perhitungan rasio efektivitas sebagai berikut.

$$
\begin{aligned}
\text { Rasio Efektivitas } & =\frac{\text { Realisasi Penerimaan Pendapatan }}{\text { Target Penerimaan PAD }} \times 100 \% \\
\text { Rasio Efektivitas } & =\frac{\mathrm{Rp} 450.000}{\mathrm{Rp} 27.500 .000} \times 100 \% \\
\text { Rasio Efektivitas } & =1,63 \%
\end{aligned}
$$

Berdasarkan perhitungan rasio efektifitas dan kriteria efektifitas kinerja, dapat ditarik kesimpulan bahwa rasio efektifitas dari IPLT Cibeet pada tahun 2019 hanya mencapa $1,63 \%$. Persentase rasio efektivitas tersebut mengindikasikan rasio efektifitas dari IPLT Cibeet tidak efektif karena kurang dari $60 \%$.

\section{Rasio Efisiensi}

Menurut Nurhayati (2015), rasio efisiensi adalah rasio yang menggambarkan perbandingan antara besarnya biaya yang dikeluarkan untuk memperoleh pendapatan dengan realisasi pendapatan yang diterima.

Tujuan analisis dimensi ekonomi adalah untuk meningkatakan Pendapatan Asli Daerah (PAD). Menurut Alhusain et al. (2017) berpendapat bahwa strategi dan kebijakan peningkatan PAD merupakan salah satu modal keberhasilan dalam mencapai tujuan pembangunan daerah.

\subsubsection{Dimensi Lingkungan}

Kinerja lingkungan diukur dengan menggunakan 1 (satu) indikator yakni dampak aset terhadap lingkungan. Indikator untuk menilai kinerja lingkungan diadaptasi dari Nasrullah (2007). Dampak aset terhadap lingkungan merupakan hal penting yang harus diperhatikan karena dapat menimbulkan masalah kesehatan, kenyamanan, ketertiban, dan keindahan bagi lingkungan. Pembangunan IPLT harus memperhatikan pertimbangan 
lingkungan sebagai salah satu kriteria pokoknya. Apabila tidak, maka pembangunan IPLT tersebut akan dapat mengakibatkan kerugian, baik kerugian fisik (alam lingkungan) maupun non fisik (sosio budaya) pada lingkungan sekitarnya.

Berdasarkan hasil wawancara dengan karyawan IPLT Cibeet dan Kepala UPTD Instalasi Pengolahan Limbah Domestik, adannya IPLT Cibeet ini berdampak terhadap lingkungan sekitar. Contohnya terdapat resiko pencemaran kualitas air jika terdapat kerusakan/kebocoran pada instalasi dan masalah bau dikarenakan tidak adanya proses pengolahan lumpur tinja pada IPLT Cibeet. IPLT Cibeet digunakan hanya sebagai tempat pembuangan lumpur tinja saja tanpa adanya proses pengolahan lumpur tinja. Selain itu, dalam bidang partisipasi masyarakat, kesadaran masyarakat tentang pengelolaan air limbah domestik yang berkelanjutan dari pembuangan awal hingga pembuangan akhir masih rendah yang dibuktikan dengan sekitar 60-70\% limbah domestik mencemari sungai citarum.

Dampak negatif tersebut berupa pencemaran kualitas air jika terdapat kerusakan/kebocoran pada instalasi dan masalah bau dikarenakan tidak adanya proses pengolahan lumpur tinja pada IPLT Cibeet. Namun. kegiatan operasional IPLT Cibeet tidak berlangsung setiap hari bahkan sering menganggur mengakibatkan dampak yang ditimbulkan tidak berlangsung setiap hari dan hanya terjadi saat proses pembuangan lumpur tinja saja.

\section{KESIMPULAN DAN SARAN}

\subsection{Kesimpulan}

Hasil evaluasi kinerja aset Instalasi Pengolahan Lumpur Tinja (IPLT) Cibeet di Kabupaten Bandung, menunjukkan bahwa:

1. Pada dimensi teknis kinerja IPLT Cibeet buruk, karena terdapat satu unit instalasi dan fasilitas pendukung yang tidak tersedia,ketersediaan unit instalasi dan fasilitas pendukung tidak sesuai standar. Kondisi unit instalasi dan fasilitas pendukung rusak ringan, terdapat komponen pada unit instalasi yang rusak. Alasan kegiatan operasional belum optimal karena penggunaan IPLT tidak sesuai tupoksi, intensitas penggunaan masih sangat rendah, dan tiap unit IPLT tidak beroperasi sesuai dengan fungsinya.

2. Pada dimensi ekonomi kinerja IPLT Cibeet buruk, karena tidak efisien dan tidak efektif karena rasio efektivitas hanya mencapai $1,63 \%$ dan jika dihitung dari rasio efisiensi mengalami kerugian karena biaya yang dikeluarkan lebih besar dari 
pendapatan yang diterima. Hal tersebut menjelaskan bahwa IPLT Cibeet dinilai belum bisa meningkatkan PAD.

3. Pada dimensi lingkungan kinerja IPLT Cibeet buruk, karena terdapat pencemaran kualitas air jika terdapat kerusakan/kebocoran pada instalasi dan masalah bau dikarenakan tidak adanya proses pengolahan lumpur tinja pada IPLT Cibeet.

\subsection{Saran}

Berdasarkan kesimpulan yang telah dijelaskan sebelumnya

1. Berdasarkan kinerja pada dimensi teknis, maka dalam memenuhi ketersediaan perlu dilakukan pembangunan unit instalasi dan fasilitas pendukung yang tidak tersedia yaitu pada bak pengumpul dan laboratorium. Selain itu perlu dilakukannya pembangunan ulang sesuai dengan standar untuk unit instalasi dan fasilitas pendukung yang tidak sesuai dengan kriteria desain. Dalam mengatasi unit instalasi dan fasilitas pendukung yang rusak perlu dilakukannya perbaikan dan pemeliharaan secara rutin. Upaya yang dapat dilakukan untuk mengatasi permasalahan fungsi/status beroperasinya IPLT, perlu dilakukannya peningkatan kegiatan operasional sesuai dengan standar yang berlaku. Peningkatan kegiatan operasional sesuai dengan standar yang berlaku dilakukan untuk meningkatkan intensitas penggunaan setiap tahunnya dan setiap unit instalasi tetap beroperasi secara maksimal agar penggunaan IPLT dapat sesuai dengan tupoksinya.

2. Berdasarkan kinerja pada dimensi ekonomi dan dimensi lingkungan, maka perlu adanya peningkatan program pemenuhan kegiatan operasional di IPLT Cibeet agar pendapatan dari IPLT Cibeet meningkat sesuai dengan target PAD yang telah ditetapkan dan menghindari pencamaran lingkungan. Pemenuhan kegiatan operasional dilakukan dengan cara melakukan dan memperbaiki proses pengolahan lumpur tinja secara terstruktur di IPLT Cibeet dari proses penyedotan lumpur tinja hingga proses pengolahan dan hasil dari pengolahan IPLT.

\section{DAFTAR PUSTAKA}

Alhusain, A. S., Mauleny, A. T., Nidya, W. S., \& Lisnawati. (2017). Kebijakan dan Strategi Peningkatan Pendapatan Asli Daerah dalam Pembangunan Nasional. Yayasan Pustaka Bogor Indonesia.

Australian Asset Management Collaborative Group. (2012). Guide to integrated strategic asset management. CRC Australia. 
Australian Asset Management Collaborative Group. (2008). Public Sector Asset Performance and Reporting. CIEAM.

Direktorat Jenderal Cipta Karya. (2015). Prasarana dan Sarana Sanitasi: Panduan Kualitas Visual Infrastruktur Bidang Cipta Karya. Kementrian Pekerjaan Umum.

Direktorat Jenderal Cipta Karya. (2016). Buku A Panduan Perencanaan Teknik Terinci Bangunan Pengolahan Lumpur Tinja. Kementrian Pekerjaan Umum.

Nasrullah. (2007). Studi Kelayakan Instalasi Pengolahan Lumpur Tinja Kota Salatiga. Studi Kelayakan Instalasi Pengolahan Lumpur Tinja Kota Salatiga, 3(2), 16-24. https://doi.org/10.14710/presipitasi.v3i2.16-24

Nurhayati. (2015). Analisis Rasio Keuangan Untuk Mengukur Kinerja Pemerintah Daerah Kabupaten Rokan Hulu. Jurnal Ilmiah Cano Ekonomos, 4(33), 55-66.

Shi Kun, C., Lei, Z., Ming Yue, Z., Xue, B., Zi Fu, L., \& Mang, H. P. (2017). Assessment of two faecal sludge treatment plants in urban areas: Case study in Beijing. International Journal of Agricultural and Biological Engineering, 10(3), 237-245. https://doi.org/10.3965/j.ijabe.20171003.3067

Sugiama, A. G. (2013). Manajemen Aset Pariwisata (Edisi Pertama). Guardaya Intimarta.

Uddin, W., Hudson, W. R., \& Haas, R. C. G. (2013). Public Infrastructure Asset Management, Second Edition. McGraw Hill Professional. 